\title{
APORTES TEÓRICOS E METODOLÓGICOS PARA A CONSTITUIC̣ÃO DE UM GRUPO DE PLANEJAMENTO CONJUNTO COM DOCENTES DA LICENCIATURA EM FÍSICA
}

\author{
João Ricardo Neves da Silva* \\ Lizete Maria Orquiza de Carvalho**
}

RESUMO: Apresenta-se, neste artigo, parte dos resultados de uma pesquisa que teve por intenção promover um espaço de interação comunicativa entre os docentes da licenciatura em Física a fim de que pudessem planejar suas disciplinas em conjunto. A partir das recomendações da Teoria da Ação Comunicativa, de Jürgen Habermas, foi possível traçar um cenário da crise de racionalidade na formação em licenciatura em Física no Brasil e, então, propor a criação de um Grupo de Planejamento Conjunto (GPC) com professores de disciplinas de cunho específico da Física e de ensino de Física para a discussão conjunta da relação entre suas disciplinas na concretização de um projeto de formação de futuros professores. Todas as reuniões desenvolvidas ao longo de um ano letivo nos dois GPC foram gravadas, transcritas e analisadas de acordo com um recurso metodológico de análise das interações intersubjetivas de influência habermasiana, desenvolvido especificamente para a pesquisa. As conclusões se relacionam às construções conjuntas empreendidas, aos contextos locais do GPC e à possibilidade de extensão desse grupo. As construções conjuntas empreendidas no grupo apontam para a defesa da formação de GPC nas licenciaturas em Física como formação do docente universitário que leciona essa disciplina.

Palavras-chave: Grupos de Planejamento Conjunto. Docência universitária. Licenciatura em Física. Teoria da Ação Comunicativa.

THEORETICAL AND METHODOLOGICAL CONTRIBUTIONS TO THE FORMATION OF JOINT PLANNING GROUPS WITH TEACHERS OF PHYSICS DEGREE COURSE

ABSTRACT: We present in this paper parts of the results of a research that had the intention to promote a space of communicative interaction among teachers of an undergraduate Course of Physics Teaching so they could plan their courses together. From the theoretical recommendations of the Theory of Communicative Action, by Jürgen Habermas, it was possible to draw a way of rationality crisis in training degree in physics in Brazil and then propose the creation of a Joint Planning Group (JPG) with teachers of specific nature disciplines of physics and disciplines about physics teaching. They start a joint discussion about the relationship among the disciplines in delivering of a project for future high school teachers' training. All meetings developed over a school year in the GPC were recorded, transcribed and analyzed with a part of a methodological analysis feature of the intersubjective interactions. This methodology was developed specifically for the research. The conclusions are related to the joint constructions developed by the JPG, its local contexts and the possibility of extension of this group. The joint constructions undertaken in the group point to the defense of the formation of JPG in the formation of the professors who teach these courses.

Keywords: Set Planning Groups. Physics Education Course. Theory of Communicative Action.

DOI - http://dx.doi.org/10.1590/1983-2117201416020?

Revista Ensaio | Belo Horizonte | v.16 | n. 02 | p. 85-106 | maio-ago | 2014 


\section{INTRODUCุão}

Neste artigo são expostos os resultados de uma investigação que visou formar conhecimentos sobre um cenário bastante denunciado nos textos da literatura especializada que versam sobre a formação do professor nos cursos de licenciatura em Física. Tal cenário, sobre o qual existem poucas pesquisas, diz respeito aos problemas referentes às relações entre as disciplinas de cunho específico e de ensino e à interação entre os docentes nos cursos de licenciatura em Física no contexto da universidade pública atual. Nesse sentido, a pesquisa lidou com um aspecto bastante subjetivo da formação nos cursos de licenciatura em Física, que se refere às posturas teóricas e práticas dos docentes que lecionam disciplinas específicas e disciplinas de ensino nesses cursos, em comparação com as validades e importâncias que esses docentes concedem aos aspectos da formação de professores.

Com o apoio das críticas realizadas por Chauí (2001), Cunha (2002), Goergen (1998) e Freitas (2008), desenvolveu-se uma pesquisa a partir da constatação do cenário de uma universidade pública da modernidade, que concede pouca ou nenhuma importância aos aspectos referentes à construção de conhecimento ou à emancipação dos estudantes em comparação ao desenvolvimento de "destrezas técnicas" para a lida profissional (CUNHA, 2002).

Em conexão com o cenário apontado por Habermas e seus divulgadores de dominação da racionalidade emancipatória (MUHL, 2003) pelas questões burocráticas do sistema e pela racionalidade técnica instrumental, tem-se o fato de que, nessa estrutura universitária da modernidade instrumentalmente racionalizada e que cada vez mais se vê frente ao desafio de oferecer mão de obra para a produção de ciência e tecnologia lucrativa, observa-se os cursos de licenciatura em Física serem vitimados por uma invasão de pressupostos que fazem com que, mesmo nesses cursos, a formação do estudante seja pensada de forma a atender às necessidades da pesquisa em ciência e do desenvolvimento tecnológico aplicado ao mercado. Nesse contexto, a formação do professor passa a estar em segundo plano mesmo nos cursos de licenciatura, nos quais a grande maioria dos docentes têm formação em bacharelado e desenvolvem pesquisa em áreas que não se envolvem com o ensino de Física.

Além disso, outro reflexo da forma de racionalizar da sociedade atual, especificamente no campo deste estudo, é exatamente a prática das disciplinas pelos acadêmicos que lecionam na licenciatura e que, em sua maioria, não estabelecem relações com as questões do ensino, o que é de importância fundamental na formação do futuro professor de Física.

Alguns trabalhos mostram que ensinar ciências requer profundas mudanças nas concepções pedagógicas dos professores. Exige do profissional não apenas um profundo conhecimento do conteúdo científico (específico) e pedagógico, mas também a interação entre os conteúdos das disciplinas de cunho específico com os das disciplinas pedagógicas (ZIMMERMANN e BERTANI, 2003, p. 45). 
No que se refere à formação de futuros professores de Física, esse panorama da universidade da modernidade se reflete em uma desvalorização do ensino na graduação, o que, consequentemente, faz com que muitos docentes não concedam as necessárias validades ou se dediquem aos aspectos da formação de seus alunos. Freitas (2008) afirma que:

\begin{abstract}
No que se refere à docência, Chauí (2001) constata que sua essencial, cuja conferir repetição da palavra "marca" é a produção de conhecimento, desapareceu completamente, uma vez que não é dado mais o tempo necessário à atividade cognitiva, para que haja crítica, exame de conhecimento instituído, mudança e superação. A docência que passa a representar posse de instrumento para intervir e controlar alguma coisa, é entendida como uma forma de o graduado ingressar no mercado de trabalho de modo rápido, ou ainda como uma etapa para o treinamento de novos pesquisadores, de qualquer modo, precarizando tanto a docência quanto a pesquisa naquilo que a autora considera ser sua marca essencial, a formação (FREITAS, 2008, p. 17).
\end{abstract}

Envolve-se, então, nesta argumentação e nesta pesquisa, com um contexto no qual, nos cursos de licenciatura em Física no Brasil, há uma série de conflitos de importâncias e validades que acabam por determinar a forma como esses cursos de formação de professores são conduzidos. Ostermann (2001) descreve esse conflito quando diz:

Nas críticas feitas ao documento das diretrizes (BRASIL, 2002), fica claro o descontentamento da comunidade científica, ligada à Física, com o proposto para a formação dos professores. Nas diretrizes para a formação de graduados em Física, a formação inicial do professor de Física é uma das ênfases da graduação em Física, ou seja, identifica esse profissional como um físico com uma dada especialização em educação. Os físicos demonstram querer que o professor de Física não se afaste da Física como ciência específica. Já na proposta das Diretrizes do MEC: "As licenciaturas passam a ser identificadas entre si, e não às suas áreas específicas, a partir de uma dimensão comum. Trata-se, portanto, de concepções de formação de professores distintas (OSTERMANN, 2001, p.01).

Ou seja, para muito além dos aspectos de ordem ou carga horária das disciplinas, a concretização de certas ideologias e necessidades apontadas pela pesquisa em ensino de Física sobre a formação de professores de ciências passa pelo fato de os docentes que lecionam as disciplinas na licenciatura não serem necessariamente envolvidos na área de ensino de ciências e, portanto, delegarem outras importâncias ou funções às disciplinas que lecionam.

Puentes e Aquino (2009), ao descreverem o papel da docência na universidade, ressaltam o fato de que essa "parte" das funções de um docente universitário parece não gozar do mesmo prestígio que a de pesquisador, talvez por não ter um caráter profissional, com funções bem delimitadas dentre as suas atribuições, como defende : 
Em outras palavras, a docência universitária, mais que ensinar os conhecimentos de uma ciência, deveria ter por missão ensinar a pensar uma determinada ciência e pensar cientificamente seus conhecimentos, por meio da capacidade de garantir e integrar a dupla compreensão dos processos científicos e dos usos das ciências: a produção de conhecimento e sua aplicação. Em definitivo, o papel da docência universitária deveria ser o de ajudar o aluno a pensar e agir mediante os instrumentos conceituais e os processos de investigação da ciência que o professor ensina (PUENTES; AQUINO, 2009).

Ou seja, seria ideal nesse processo que o docente universitário construísse, pelas vias de sua formação, a consciência da diferenciação entre os aspectos que abrangem sua função de docente e de pesquisador, sem uma diferenciação de importância entre elas. Contudo, em um contexto em que a produção científica é tida como justificativa de investimentos ou mesmo de estudos, essa diferenciação pode ser descrita como consequência de uma história da universidade dominada pela racionalidade com respeito a fins.

Dessa maneira, há na licenciatura em Física um ambiente no qual a maioria das discussões aqui apresentadas não são tidas como importantes ou mesmo levadas em consideração, pois os docentes responsáveis pela concretização desses projetos não "enxergam" a melhoria da licenciatura como um passo que deva ser dado, ou mesmo não se relacionam com essa problemática.

No intento de explorar essa complexa problemática por um ponto de vista com o qual possamos fundamentar os vários subtemas que a compõe, nos pautamos nos referenciais teóricos oriundos da chamada "Teoria Crítica da Sociedade", com especial afinco às ideias de racionalidade, comunicação e progresso científico do sociólogo Jürgen Habermas, o que nos abre um leque de possibilidades e de interpretações bastante condizente com as ideologias que buscamos enfatizar nesta pesquisa.

Com o contexto apresentado anteriormente, foi proposto o desenvolvimento e a análise de uma experiência de formação de um Grupo de Planejamento Conjunto (GPC) com professores das disciplinas de cunho específico e pedagógico na licenciatura, a fim de formar conhecimento sobre a seguinte questão de pesquisa: Como os docentes responsáveis pelas disciplinas que envolvem os conteúdos especificos e pedagógicos em cursos de licenciatura em Física se comunicam entre si e quais os conbecimentos produzidos pela participação dos docentes em um Grupo de Planejamento Conjunto (GPC)?. Essa questão de pesquisa fica mais visível quando auxiliada pelas três questões seguintes:

"Quais as possibilidades de instauração de um processo comunicativo que vise ao desenvolvimento de uma ação comunicativa entre os participantes de um GPC?” "Quais os conhecimentos sobre os cursos e as disciplinas produzidos pelos participantes em um GPC que se pretende comunicativo?"

"Quais são os efeitos de um planejamento de grupo pretensamente pautado em princípios da TAC e da investigação-ação?"

Com essas questões, os objetivos da pesquisa podem ser pontuados da seguinte maneira: 
- Promover um Grupo de Planejamento Conjunto (GPC) com docentes da licenciatura em Física sobre as possibilidades de aproximação entre as disciplinas que abordam o tema Física Moderna e Contemporânea (FMC) e a Instrumentação para o Ensino de Física (IEF).

- Analisar a forma como acontecem as interações entre os docentes durante as reuniões do grupo, baseando-se nos preceitos da Teoria da Ação Comunicativa (TAC)

- Identificar quais os conhecimentos sobre a licenciatura e a relação entre as disciplinas específicas e de ensino formada pela interação dos docentes no GPC.

Com esses objetivos, então, estuda-se a pertinência da proposição de ambientes de possibilidade de debate e planejamento como forma de construir, in loco, juntamente com os docentes em grupos de trabalho, elementos necessários à reflexão sobre as necessidades da formação do licenciando.

\section{REFERENCIAIS TEÓRICOS}

Para fundamentar a construção de um processo de interação entre alguns docentes da licenciatura em Física, o trabalho se pauta em referenciais teóricos e metodológicos oriundos de uma concepção crítica de formação. $\mathrm{Na}$ área de ensino de ciências há poucos, mas significativos trabalhos acadêmicos que analisaram essas proposições para entender os processos de constituição de grupos de professores e alunos, tais como Chapani (2010) e Sutil (2011). Já na área de educação, há uma série de pesquisas que se dedicam a compreender a relação do processo educativo com as questões sobre a modernidade no sentido da teoria crítica, tal como Muhl (1999), Longhi (2005), Gomes (2005), entre outros. Esses trabalhos serão apoios para a elucidação do referencial aqui apresentado em relação com a área do ensino a que se destina.

Tanto para fundamentar a criação e a manutenção do grupo como para compreender as características da comunicação instaurada ao longo do processo de planejamento conjunto, nos fundamentamos nas características defendidas por Jürgen Habermas na sua Teoria da Ação Comunicativa (TAC) e nas interpretações desta para a educação a partir dos autores supracitados. Segundo o autor, o conceito de racionalidade comunicativa e, consequentemente o de agir comunicativo, perpassa pela ideia de uso racional da linguagem ou interação linguisticamente mediada (HABERMAS, 2012). A linguagem ganha o status de "meio" a partir do qual o entendimento entre pessoas é possível, ou, como nas palavras de Longhi, "O que torna a racionalidade comunicativa possível é o médium linguístico, através do qual as interações se interligam e as formas de vida se estruturam" (LONGHI, 2005, p. 16). Ou seja, nessa perspectiva teórica, o uso da linguagem em um grupo de pessoas é a forma pela qual se pode buscar um entendimento das questões em debate. Dessa maneira, alguns conceitos da TAC se tornam importantes no 
entendimento das possibilidades de formação de um GPC com docentes da licenciatura em Física. São eles:

Pretensões de validade: são as expressões manifestadas por meio de exteriorizações reconhecíveis e acessíveis à análise racional; ou seja, quando um falante que pretende uma ação comunicativa levanta uma pretensão de validade, ele deve se posicionar de forma que sua asserção possa ser racionalmente analisada pelo grupo por meio dos argumentos (HABERMAS, 2012).

As pretensões de validade emitidas podem ter características e funções diferentes dentro da tentativa de entendimento, sendo elas dos seguintes tipos: descritivas, normativas, avaliativas e explicativas; e essa diferenciação determina a forma como elas serão validadas e questionadas pelos ouvintes. Habermas explica basicamente as diferenças como:

\begin{abstract}
Uma análise das formas do enunciado sob um enfoque semântico faz chegar aos mesmos modos de ser. Sentenças descritivas, que em sentido amplo, servem à constatação dos fatos, podem ser afirmadas ou negadas sob o aspecto da verdade de uma proposição; sentenças normativas (ou obrigacionais), que servem à justificação das ações, sob o aspecto da correção (ou da justeza) de um modo de agir; sentenças avaliativas (ou juízos de valor), que se prestam à valoração de algo, sob o aspecto da adequação dos padrões valorativos (ou sob o aspecto do que é bom); e explicações, que servem para esclarecer operações como falar, classificar, fazer cálculos, deduzir, julgar, etc., sob o aspecto da compreensibilidade ou boa formulação das expressões simbólicas (HABERMAS, 2012, p. 85).
\end{abstract}

Um resumo das características principais de cada um dos tipos de pretensões de validade e da fundamentação necessária à compreensão desses significados é apresentado no quadro a seguir:

Quadro 1: Características principais dos quatro tipos de pretensões de validade. (Adaptado de HABERMAS, 2012, p. 85)

\begin{tabular}{|c|c|}
\hline Tipo de pretensão de validade & Características principais \\
\hline Descritivas & $\begin{array}{c}\text { A fundamentação dos enunciados descritivos significa a } \\
\text { comprovação da existência dos estados das coisas. }\end{array}$ \\
\hline Normativas & $\begin{array}{c}\text { A fundamentação dos enunciados normativos significa a } \\
\text { comprovação da aceitabilidade das ações ou das normas } \\
\text { para as ações. }\end{array}$ \\
\hline Avaliativas & $\begin{array}{c}\text { A fundamentação dos enunciados avaliativos significa a } \\
\text { comprovação das condições de preferência dos valores. }\end{array}$ \\
\hline Explicativas & $\begin{array}{c}\text { A fundamentação dos enunciados explicativos significa } \\
\text { a comprovãão de que expressões simbólicas são } \\
\text { realmente geradas. }\end{array}$ \\
\hline
\end{tabular}

Mundo da vida: Habermas mostra a necessidade de que a racionalidade seja expressa abrangendo não somente a interação homem-objetos - mundo objetivo -, 
mas também ao que pertence ao mundo subjetivo - das questões de vivência pessoal próprias de cada sujeito - e ao mundo social - dos fenômenos sociais que poderiam influenciar o processo de racionalização. Dessa maneira, o autor propõe que se pense a racionalidade como uma capacidade de intersubjetivação das instâncias do mundo e de seus componentes; ou seja, para muito além da posse do conhecimento, também são importantes as formas como os sujeitos se comunicam sobre o mesmo a partir do uso consciente da linguagem e com argumentos advindos de qualquer dos três "mundos". A esse mundo, no qual as manifestações dos falantes podem advir de qualquer uma das três instâncias, Habermas chama "mundo da vida" (HABERMAS, 2012).

Em suas realizações interpretativas, os envolvidos em uma comunidade de comunicação estabelecem limites entre o mundo objetivo único e seu mundo social intersubjetivamente partilhado, de um lado, e os mundos subjetivos de indivíduos e de outras coletividades. As concepções de mundo e as pretensões de validade correspondentes constituem o arcabouço formal com que os que estão agindo comunicativamente ordenam os respectivos contextos situacionais problemáticos (isto é, carentes de acordo), dispondo-os em seu mundo da vida pressupostos de maneira não problemática (HABERMAS, 2012, p. 138).

Assim, quando uma discussão de pretensões de validade acontece no âmbito do mundo da vida, pode-se dizer que todas asserções são postas a partir de uma compreensão mútua de que o tema pode ser discutido levando-se em conta os elementos objetivos, subjetivos e sociais que o envolvem para que esteja em curso a tentativa de entendimento, sem considerar as influências externas e que não fazem parte das três instâncias. Isso é o que Habermas quer dizer quando defende que os temas sejam "dispostos em seu mundo da vida de forma aproblemática" (HABERMAS, 2012). Dessa maneira, o mundo da vida se constitui no "lugar" a partir do qual se pode racionalizar sobre um objeto de estudo referenciando-se em elementos advindos de todas as três instâncias.

Pensando em completar metodologicamente os processos que envolvem grupos de pessoas empenhadas em, com um trabalho conjunto, conhecer mais sobre situações nas quais estão imersas, apoia-se também em um referencial teórico de vertente crítica que apresenta uma sistematização de ideias que se encontram com as nossas: a investigação-ação. Essa vertente se dissipou nos últimos 30 anos nas pesquisas em educação que intencionavam constituir conhecimentos sobre a participação ativa dos membros dos grupos nas mudanças efetivas das realidades que pesquisavam (ROSA; SCHNETZLER, 2003), (TRIPP, 2005), tornando-se "uma metodologia preferencial nas práticas educativas" (COUTINHO, 2009).

Coutinho (2009) argumenta que a teorização de Carr e Kemmis sobre a investigação-ação, baseada em Habermas, mostra como esta se distancia do paradigma positivista até então dominante na pesquisa educacional e se aproxima de um paradigma sociocrítico, segundo o qual “a investigação-ação não só se constitui como uma ciência prática e moral como também como uma ciência crítica" (p. 360): 
Ao distanciar-se dos paradigmas positivista e interpretativo pelo excessivo objetivismo e neutralidade do primeiro e pela propensão para a subjetividade do segundo, o paradigma sócio-crítico traz para a ribalta das práticas investigatórias a concepção ideológica e valorativa que está presente na investigação e que acaba por determinar o conhecimento que daí possa advir. Por outro lado, e na senda dos princípios filosóficos de Jürgen Habermas sob os quais uma investigação deve sempre conter em si uma intensão de mudança, este paradigma faz também incidir o seu foco sobre o conhecimento emancipatório, que pretende por a nu as ideologias que condicionam o acesso ao conhecimento e operar ativamente na transformação da realidade (COUTINHO, 2009, p. 357).

E dessa maneira, traçam-se relações da teoria social crítica com a proposta de investigação segundo a qual "para além da crítica, se aborde a práxis crítica; isto é, uma forma de prática em que a ilustração dos agentes tenha sua consciência direta em uma ação social transformada” (CARR e KEMMIS, 1988, p. 157).

Contudo, dadas as premissas fundamentadoras dessas propostas e a realidade dos sistemas educacionais em nível mundial, este se torna um trabalho de extrema dificuldade, pois exige que "os docentes se convertam em investigadores de suas próprias práticas, seus entendimentos e suas ações” (CARR e KEMMIS, 1988, p. 173, tradução nossa), o que não é uma forma de pensar comum nos espaços considerados, em sua maioria de prioridades sistêmicas.

Segundo esses autores, um projeto no qual os professores se envolverão nesses termos se inicia com a identificação de uma "preocupação temática", que é uma área ou uma situação em que os participantes devem querer se envolver, pois abarcam "preocupações de influência mútua” (KEMMIS e MCTAGGARD, 1988, p. 11). Em outras palavras, para garantir que os professores adentrarão a discussão das questões com uma profundidade necessária à formação de esclarecimentos sobre ela, é preciso que se trate de um tema pelo qual todos os participantes teriam uma espécie de "empatia". Nas palavras do autor, o trabalho se inicia da segunte maneira:

a ideia geral necessita de uma exploração da circunstâncias e dos terrenos em que o problema está e o estabelecimento de fatos sobre essas circunstâncias. Uma vez que se tomam decisões sobre o terreno e se realiza uma exposição preliminar, o grupo de investigação-ação decide um plano de ação geral (KEMMIS e MCTAGGARD, 1988).

No caso do grupo de docentes estudado nesta pesquisa, com históricos de formações e concepções sobre a importância do tema tão distintas, as preocupações temáticas devem ser tais que os coloquem como importantes na contribuição de uma discussão, como é o tema das metodologias e abordagens do ensino de FMC na licenciatura e a melhora da interação entre suas disciplinas, por exemplo. Evidentemente, as diferentes concepções e os conflitos de pretenções de validade são importantes no processo de construção de consensos; contudo, a identificação e a apropriação da necessidade do debate do tema é algo essencial para o progresso do projeto de investigação-ação.

Assim, temos que os sujeitos participativos se envolvem com o tema em forma de pesquisa. Eles entram em contexto de debate para pretenderem buscar 
o entendimento sobre as ações necessárias para a melhora daquele cenário em que a preocupação temática se encontra, planejam ações que podem ser realizadas individualmente e em conjunto para alcançar os objetivos definidos, executam essas ações, retornam ao grupo para discutir e refletir sobre elas e fazem planejamentos de novas ações.

Dessa maneira, e de acordo com concepções teórico-metodológicas que orientam um trabalho de investigação-ação, foi que se desenvolveu uma proposta visando promover a aproximação entre os docentes que lecionam disciplinas relacionadas em dois cursos de licenciatura em Física, por meio da criação de oportunidades de debater sobre a necessidade e as formas de se promover uma maior interação entre essas disciplinas. Assim, espera-se que esses docentes se envolvam em um projeto de mudança da realidade dos cursos em que lecionam Física para a formação de professores.

\section{OS ENCAMINHAMENTOS METODOLÓGICOS}

A partir das considerações teóricas sobre as possibilidades advindas do debate pautado em uma ação comunicativa e dos conceitos gerais apresentados, desenvolveu-se uma metodologia de grupo de discussão que tinha como "norte" algumas características apontadas pelo referencial como necessárias ao desenvolvimento de um ambiente pretensamente de "ação comunicativa", tais como: equidade de oportunidades de fala, tematização da prática, revisão constante do estado das coisas (HABERMAS, 2012).

Devido ao fato de o trabalho apresentar certas ligações com a área de Física Moderna e Contemporânea, foram convidados os docentes que lecionam as disciplinas que podem se relacionar com essa temática na licenciatura em Física, além dos docentes responsáveis pelas disciplinas de Instrumentação para o Ensino de Física. Essas disciplinas foram escolhidas considerando as seguintes pretensões de pesquisa:

a) Há poucos estudos na área de Ensino de Ciências relacionados ao ensino de Física Moderna e Contemporânea nos cursos de licenciatura em Física.

b) As disciplinas Estrutura da Matéria (EM) e Laboratório de Estrutura da Matéria (LEM), presentes nas estruturas curriculares do curso de licenciatura em Física estudado, possibilitam uma discussão bastante nova sobre os pontos de relacionamento entre seus conteúdos, uma vez que é de desconhecimento da maioria dos docentes da universidade as propostas de inserção de Física Moderna e Contemporânea no Ensino Médio.

c) Há a possibilidade de busca conjunta de aproximações entre essas duas disciplinas específicas, que são disciplinas pouco consideradas nos projetos de formação de professores de Física.

d) A disciplina de Instrumentação para o Ensino de Física (IEF) representa a possibilidade de busca conjunta de relações entre as disciplinas de cunho específico e a disciplina de ensino. 
e) Há a possibilidade de estímulo ao trabalho com conteúdos de Física Moderna e Contemporânea na disciplina de IEF, uma prática ainda pouco difundida nos cursos de licenciatura em Física (OSTERMANN, 2002).

f) O histórico pregresso de pesquisa e estudos do pesquisador na área de FMC, ponto necessário à manutenção de uma discussão com "iguais oportunidades de fala" e com iguais possibilidades de levantamento de pretensões de validade.

Sendo assim, os docentes que lecionam essas três disciplinas citadas no curso de licenciatura em Física em questão foram chamados para uma conversa inicial individual com o pesquisador. Nessas condições, apresenta-se a caracterização dos docentes convidados a participar do grupo estudado neste trabalho, que apresentam os seguintes perfis:

Quadro 2: Caracterização dos docentes participantes da pesquisa

\begin{tabular}{|c|c|}
\hline Docente & Perfil \\
\hline 1 & $\begin{array}{l}\text { Licenciado em Física com mestrado e doutorado na área de ciências } \\
\text { dos materiais com pesquisa em filmes finos. Professor do curso desde } \\
1988 \text { das disciplinas de Laboratório de Física e Astronomia Básica. } \\
\text { Coordenador de um centro de ciências no campus da universidade. } \\
\text { Docente da disciplina LEM no curso de licenciatura em física do curso. }\end{array}$ \\
\hline 2 & $\begin{array}{l}\text { Licenciado em Física e bacharel em Engenharia de Materiais com } \\
\text { mestrado e doutorado na área de ciências de materiais com pesquisas } \\
\text { em filmes finos. Professor do curso desde } 2004 \text { nas disciplinas de Física } \\
\text { Básica e EM. Orientador de mestrado e doutorado em programa de Pós- } \\
\text { Graduação em Ciência e Engenharia de Materiais. Docente da disciplina } \\
\text { EM no curso de licenciatura em Física. }\end{array}$ \\
\hline 3 & $\begin{array}{l}\text { Licenciado em Física com mestrado e doutorado na área de educação } \\
\text { para a ciência com pesquisas em História da Física e Aprendizagem. } \\
\text { Orientador de mestrado e doutorado em Programa de Pós-Graduação } \\
\text { em Educação para a Ciência. Professor do curso desde 2009. Docente da } \\
\text { disciplina IEF no curso de licenciatura em Física. }\end{array}$ \\
\hline
\end{tabular}

Os docentes foram convidados para uma entrevista inicial com o pesquisador para a exposição das ideias do trabalho e entendimento individual das premissas envolvidas. Nessa entrevista inicial, foram tematizadas as opiniões gerais dos docentes sobre o curso, suas disciplinas, a relação entre as disciplinas. A partir das concepções apresentadas nessa entrevista e das possibilidades percebidas pelo pesquisador, foi, então, realizado o convite para a participação em um grupo com os outros docentes.

Dessa maneira, os docentes das disciplinas de Instrumentação para o Ensino de Física (docente 3), Estrutura da Matéria (docente 2) e Laboratório de Estrutura da Matéria (docente 1) de um curso de licenciatura em Física de uma universidade pública, juntamente com o pesquisador, iniciaram o processo de constituição de um GPC que se dedicou a estudar, debater e planejar em conjunto suas disciplinas e elucidar as possíveis características que essas poderiam apresentar por serem desenvolvidas em um curso de formação de professores. 
Durante as reuniões foi seguida a premissa de encontrarmos as "preocupações temáticas" (CARR; KEMMIS, 1987) comuns do grupo, ou seja, a partir de roteiros elaborados pelo pesquisador, os debates eram conduzidos de modo a permitir que se enfatizasse e se discutisse com mais afinco aqueles assuntos sobre os quais os docentes tinham uma maior identificação comum, visando promover um debate validado no contexto dos docentes.

O quadro 3 mostra detalhadamente os assuntos debatidos em cada reunião realizada durante um ano letivo:

Quadro 3: Intencionalidades e resumo dos assuntos discutidos em cada reunião realizada no GPC

\begin{tabular}{|c|c|c|}
\hline REUNIÃO & DATA & TEMÁTICA \\
\hline 1 & 05/05/2012 & $\begin{array}{l}\text { Apresentar o tema da pesquisa, as ideias principais e } \\
\text { discutir com os professores a situaçãao do curso, a situação } \\
\text { das disciplinas em estudo, a situação do ensino de FMC no } \\
\text { Ensino Médio e propor, então, um trabalho com atividades de } \\
\text { interação entre as disciplinas. }\end{array}$ \\
\hline 2 & $06 / 06 / 2012$ & $\begin{array}{l}\text { Essa reunião tinha o objetivo de dar continuidade à anterior, } \\
\text { porém levantando a discussão sobre a necessidade de } \\
\text { se seguir o PPP (Projeto Político Pedagógico) do curso e } \\
\text { sobre as questões escritas nesse documento acerca do } \\
\text { físico-educador. Além disso, pretendia-se dar continuidade } \\
\text { à proposição de possíveis atividades a serem feitas nas } \\
\text { disciplinas visando a melhor relação entre elas. A parte II } \\
\text { da reunião, apenas com os docentes, buscou complementar } \\
\text { as discussões iniciadas na primeira parte da reunião II } \\
\text { e adentrar em uma discussão mais específica sobre a } \\
\text { organização das atividades a serem realizadas no projeto de } \\
\text { aproximação entre as disciplinas }\end{array}$ \\
\hline 3 & $13 / 07 / 2012$ & $\begin{array}{l}\text { A terceira reunião foi realizada em período de férias de julho } \\
\text { e, portanto, não contou com a presença de todos os docentes. } \\
\text { Foi realizada entre os docentes } 1 \text { e } 3 \text { a fim de enfatizar a } \\
\text { aproximação entre suas disciplinas lo LEM e a IEF). }\end{array}$ \\
\hline 4 & $22 / 08 / 2012$ & $\begin{array}{c}\text { Reunião com os três docentes para iniciar os planejamentos } \\
\text { específicos no segundo semestre. A partir das constatações } \\
\text { da reunião passada entre os docentes } 1 \text { e } 3 \text {, pensamos } \\
\text { ser necessário conversar sobre as atividades que seriam } \\
\text { feitas no âmbito de cada disciplina na contribuição dessa } \\
\text { interação, mais além de contribuir somente com a disciplina } \\
\text { de instrumentação. }\end{array}$ \\
\hline 5 & $27 / 09 / 2012$ & $\begin{array}{l}\text { A quinta reunião teve por objetivo uma discussão mais } \\
\text { ampla das compreensões que cada docente estava tendo da } \\
\text { proposta, o que já haviam conseguido colocar em prática e } \\
\text { relatos das atividades realizadas até o momento. Também } \\
\text { pretendeu-se por em discussão a sistematização feita pelo } \\
\text { pesquisador do estado atual e anterior de cada disciplina. }\end{array}$ \\
\hline
\end{tabular}


Todas as reuniões de planejamento conjunto, de periodicidade mensal, foram gravadas em áudio e transcritas em busca por convergências e conclusões do processo do grupo.

Esta pesquisa, como já esclarecido, se pauta nas defesas do referencial habermasiano para compreender como o processo comunicativo desenvolvido entre os docentes pode influenciar nas suas práticas e concepções acerca de suas disciplinas no curso de licenciatura em Física. Dessa maneira, entende-se que as premissas a partir das quais Habermas constrói sua concepção de comunicação exigem uma leitura apropriada dos dados obtidos. Assim, as concepções de discurso e ação comunicativa no referencial habermasiano não poderiam ser analisadas em sua completude a partir do uso exclusivo das metodologias de análise comumente utilizadas na área de ensino (Análise de Conteúdo e Análise de Discurso, por exemplo).

Sendo assim, o que se apresenta aqui é um ensaio teórico de um "dispositivo de análise" das manifestações linguísticas baseado nas características atribuídas por Habermas ao processo comunicativo e uma proposta de sequencia de análise inspirada nesse arcabouço teórico. Para tanto, o recorte realizado da teoria dos atos de fala contribui, aqui, na diferenciação de ilocuções e perlocuções. Os atos de fala se diferenciam em três tipos: os ilocucionários, os locucionários e os perlocucionários, e se pode caracterizá-los da seguinte maneira:

- Os atos de fala locucionários: acontecem quando o falante se vale de expressões para apontar o estado das coisas, ou seja, quando se exprime uma informação, por exemplo, sobre um fato.

- Os altos de fala ilocucionários: são expressões que carregam um ato para além da fala, ou seja, quando o falante exerce uma ação com sua fala. Conselhos e informações acompanhadas de recomendações são assim consideradas.

- Os atos de fala perlocucionários: são aquelas asserções nas quais o falante intenta causar um efeito no ouvinte e esse efeito está ligado a uma intenção estratégica de conseguir o que pretende.

Sobre a "força ilocucionária dos atos de fala" (HABERMAS, 1996), fica claro, na explanação do autor, que esta está ligada à tentativa de estabelecer uma relação interpessoal sobre um assunto a ser debatido, ainda que "a tentativa que um falante faz com um ato ilocucionário poderá falhar pela recusa do ouvinte em entrar na relação proposta" (p. 89). Além disso, a pressuposição essencial para o sucesso de um ato de fala consiste em o falante assumir um compromisso específico de modo que o ouvinte possa confiar na possibilidade de efetivação do ato pelo falante. Em outras palavras, "uma expressão apenas pode ser considerada uma promessa, uma declaração, um pedido, uma pergunta ou uma confissão se o falante estiver pronto a cumprir desde que o ouvinte a aceite" (HABERMAS, 1996, p. 92). Com essa análise, destaca-se, então, a importância de se observar os momentos nos quais os atos de fala apresentam força ilocucionária na classificação de sua potencialidade comunicativa. 
Por fim, atenta-se à construção de argumentos sobre o papel do "interpretador" de uma situação de ação comunicativa. Com base no referencial habermasiano, a concepção sobre o intérprete como participante ativo nas construções comunicativas vem ao encontro das ações adotadas neste trabalho, principalmente no concernente à tentativa de desenvolvimento de uma investigação-ação. Assim, do ponto de vista analítico, a concepção sobre a participação do intérprete em Habermas abarca a metodologia adotada para esta pesquisa.

Ao discutir a ideia de interpretação em diversas análises, Habermas se posiciona a partir das ideias da hermenêutica:

Para captar (e formular) seu significado, é preciso participar de algumas ações comunicativas (reais ou imaginárias) no curso das quais se empregue de tal modo a frase mencionada que ela seja inteligível para os falantes e ouvintes e para os membros eventualmente presentes da mesma comunidade linguística (HABERMAS, 1989, p. 40).

Com isso, fica claro, para o autor, o fato de que o intérprete de um processo de ação comunicativa deve, então, fazer parte das construções linguísticas conjuntas, pois compreende-se o entendimento como interação intersubjetiva. No ponto de vista de Habermas, não há como haver uma interpretação de um observador externo, uma vez que "Ao contrário, compreender o que é dito por alguém exige a participação no agir comunicativo” (HABERMAS, 1989, p. 40). Isso está plenamente em acordo com o processo instaurado junto aos docentes, uma vez que o pesquisador - o analista - é parte integrante das discussões e das construções conjuntas.

A ação comunicativa necessita que todos estejam livres de impedimentos sistêmicos de modo que possam debater sobre as pretensões de validade postas de modo aproblemático. Por essa razão, é imprescindível que o intérprete "aceite por princípio o mesmo status daqueles cujos proferimentos querem compreender" (p. 43). Ele não está imune às tomadas de posição junto aos sujeitos. Nesse sentido, então, o pesquisador se preparava para ser compreendido como mais um participante do GPC e debater sob as iguais oportunidades de fala com os docentes participantes.

Com esse contexto, no recurso metodológico de análise, não se trata as sistematizações de referência como interpretações, pois estas são características do sujeito isolado, mas com a denominação de "sínteses do processo" construídas a partir do que for entendido pelo pesquisador como fruto da interação conjunta e, a partir dessas conclusões teóricas, são descritas as etapas do "recurso metodológico de análise da comunicação de influência habermasiana” da seguinte maneira:

Identificação dos episódios de análise - A primeira etapa da análise consiste na seleção dos episódios a partir das transcrições das reuniões. Caracterizamos como episódio a ser analisado um conjunto completo de elementos de fala que contemplam uma discussão ou um conjunto de discussões sobre um determinado tema.

Identificação dos atos de fala - Em cada episódio de análise buscamos identificar e selecionar os atos de fala. Esses atos de fala se caracterizam como emissões linguísticas com conteúdo proposicional, que pode ser dos vários tipos já descritos no referencial teórico. 
Caracterização dos atos de fala - Configura-se como a principal etapa do processo de análise. As características descritas são utilizadas como importantes para o entendimento a partir do uso de um ato de fala para cararacterizá-lo quanto à sua forma de utilização no processo comunicativo. Nessa etapa serão selecionados tanto os conteúdos proposicionais dos atos de fala, ou seja, o que está sendo dito, quanto seus elementos de força ilocucionária.

Com esse processo descrito, se estabelece que a análise dos atos de fala é realizada de duas maneiras, sendo uma análise de seu conteúdo proposicional - construções conjuntas - e uma análise pragmática do processo comunicativo. Em conjunto, o entendimento da semântica e da pragmática dos atos de fala se aproxima do que é esperado de uma análise sob o ponto de vista habermasiano.

\section{O GRUPO DE PLANEJAMENTO CONJUNTO COMO FORMAC ÃO CONTINUADA DO DOCENTE UNIVERSITÁRIO DA LICENCIATURA EM FÍSICA: ANÁLISE E INTERPRETAÇÃO DOS DADOS}

Os dados da pesquisa se constituem por elementos sintetizadores elencados no intento de levantar congruências, divergências e características desse processo, tanto no concernente às possibilidades surgidas (as construções conjuntas) quanto à análise da comunicação entre os docentes (análise pragmática).

As análises do conteúdo das entrevistas iniciais, necessárias à formação inicial do grupo, mostraram principalmente um cenário que se pode caracterizar com as seguintes sínteses, apresentadas com um exemplo de ato de fala de cada síntese:

- Descrença dos docentes na possibilidade de relação entre as disciplinas do curso.

Docente 2: Agora, na minha visão de universidade e função da universidade, não é formar cidadão... Aqui você entra cidadão e sai cidadão. Aqui você vai agregar e viver um conbecimento específico que é próprio da profissão... Ele tem que sair daqui um bom profissional cidadão, que faz muito bem a profissão dele, com muita consciência... Pra dar aula no Ensino Médio você tem que saber Física e a parte pedagógica que é a parte da formação do profissional professor...

- Histórico de completa falta de relação ou comunicação entre os docentes sobre suas disciplinas.

Docente 2: Pra você ver... Eu acho que o professor da universidade tem tantas atribuições e tantos outros serviços pra fazer que o cara não tem tempo de conversar com o outro professor, planejar em conjunto e tal...". Pesquisador: "Então... Eu acho impressionante que, para as pessoas conversarem e trocarem ideias nos cursos, a gente precise criar projetos de doutorado... Olha o nivel em que as coisas estão...

- Concepções de que o ensino de FMC no Ensino Médio é inviável por conta de sua complexidade teórica.

Docente 1: A primeira coisa que temos que pensar é o assunto, porque para o aluno a Física Moderna é um tiquinho de nada em relação aos outros conteúdos... dentro da escola. 
$\mathrm{Na}$ figura a seguir, são sintetizados alguns elementos mais representativos do cenário geral após as três entrevistas iniciais com ênfase nas asserções comuns entre os docentes.

Figura 1: Sistematização das concepções comuns entre os docentes após as entrevistas iniciais.

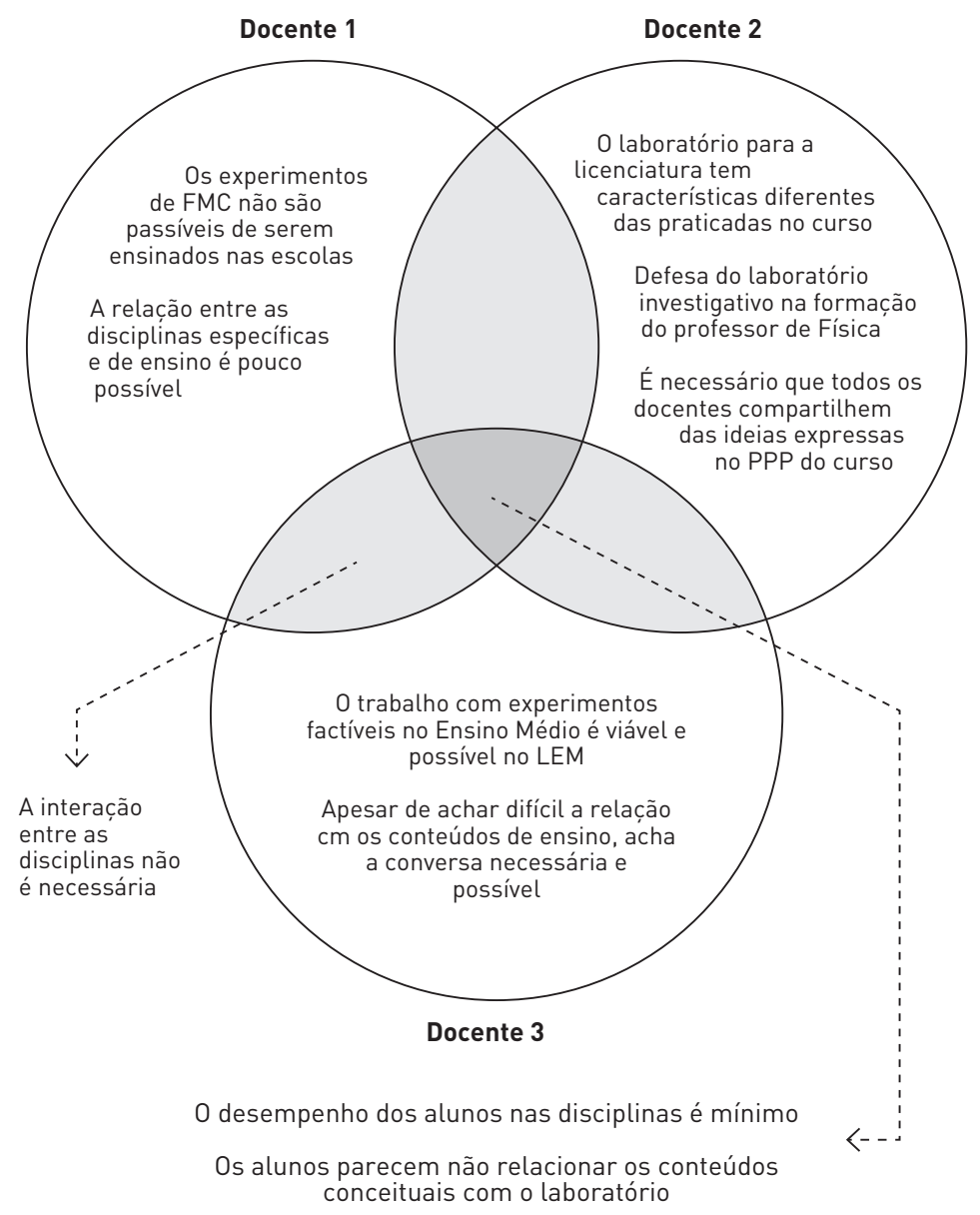

Com posse das sistematizações e das primeiras conduções proporcionadas pelas entrevistas iniciais, o grupo iniciou suas atividades de planejamento conjunto e debates em busca de pensar conjuntamente as questões levantadas nas entrevistas iniciais. 


\section{DAS CONSTRUC̣ÕES CONJUNTAS E SUA RELAC̣̃̃O COM O GPC}

Ao longo das análises das discussões ocorridas durante todo um ano letivo, o grupo começou a identificar as preocupações temáticas comuns, ou seja, os temas com os quais todos os docentes guardavam interesse e que, então, se tornaram os temas de debate. Alguns exemplos de preocupações temáticas, retirados de categorias de análise constituídas, foram:

- A dificuldade dos alunos em estabelecer relações entre os conceitos teóricos de FMC e os experimentos em LEM.

- A transposição dos conteúdos de FMC da graduação para o Ensino Médio.

- As avaliações nas disciplinas específicas e nas disciplinas pedagógicas.

- A falta de relação das disciplinas de FMC com as disciplinas de Física Clássica.

A partir do debate principalmente desses temas, o GPC foi capaz de construir conhecimentos conjuntos sobre diversos aspectos que se referem ao curso e às disciplinas, e também foi possível entender como os participantes debatem os temas de um ponto de vista da análise do processo comunicativo. Um exemplo do quadro de análise do processo comunicativo, realizado em todos os atos de fala, é exposto a seguir:

Quadro 04: Exemplo de caracterização dos atos de fala.

\begin{tabular}{|c|c|c|}
\hline Ato de fala & Características & Sínteses \\
\hline $\begin{array}{c}\text { Mas aqui no nosso curso, } \\
\text { professor, mesmo ainda que } \\
\text { estamos muito contaminados } \\
\text { pela ideia do bacharelado... } \\
\text { (Pesquisador) }\end{array}$ & $\begin{array}{l}\text { Pretensão de validade } \\
\text { avaliativa }\end{array}$ & $\begin{array}{c}\text { O docente levanta para } \\
\text { discussão um aspecto } \\
\text { avaliativo que tem do } \\
\text { curso. }\end{array}$ \\
\hline \multirow{3}{*}{$\begin{array}{c}\text { Eu não acho... Sobre essa questão } \\
\text { que você falou de bacharelado... } \\
\text { me fale um aluno que foi reprovado } \\
\text { aqui em alguma coisa porque tinha } \\
\text { licenciatura... (Docente 1) }\end{array}$} & $\begin{array}{l}\text { Discordância da pretensão } \\
\text { de validade levantada pelo } \\
\text { pesquisador. }\end{array}$ & \multirow{3}{*}{$\begin{array}{l}\text { O docente } 1 \text { não } \\
\text { concorda com a } \\
\text { pretensão de validade } \\
\text { do pesquisador, mas } \\
\text { argumenta utilizando } \\
\text { parâmetros do mundo } \\
\text { subjetivo que não } \\
\text { são partilhados pelo } \\
\text { pesquisador. }\end{array}$} \\
\hline & $\begin{array}{c}\text { Argumentação decorrente do } \\
\text { mundo subjetivo. }\end{array}$ & \\
\hline & $\begin{array}{l}\text { Levantamento de uma } \\
\text { pretensão de validade } \\
\text { avaliativa. }\end{array}$ & \\
\hline $\begin{array}{l}\text { Mas se você for em outros } \\
\text { campus, outras faculdades, você } \\
\text { vê, por exemplo, que... Quem está } \\
\text { contente com o departamento de } \\
\text { educação? (Docente 1) }\end{array}$ & Ato de fala perlocucionário. & $\begin{array}{l}0 \text { docente 1, então, } \\
\text { executa um ato de fala } \\
\text { que foge ao tema em } \\
\text { discussão, levando a } \\
\text { argumentação para } \\
\text { outro campo, impedindo } \\
\text { o entendimento. }\end{array}$ \\
\hline
\end{tabular}




\begin{tabular}{|c|c|c|}
\hline Ato de fala & Características & Sínteses \\
\hline $\begin{array}{l}\text { Então... então há sempre coisas } \\
\text { que têm que ser melhoradas... } \\
\text { Esse ponto de conversa que eu } \\
\text { coloquei aqui pra gente é apenas } \\
\text { um ponto dentre muitos que } \\
\text { precisam ser mudados, mas } \\
\text { se por conversa... Então é isso } \\
\text { professor, eu gostaria que o senhor } \\
\text { tivesse sintonizado nas propostas } \\
\text { pra gente continuar a conversa } \\
\text { sempre, como um grupo, ao menos } \\
\text { esse ano... (Pesquisador) }\end{array}$ & $\begin{array}{l}\text { Incompreensão do ato de fala } \\
\text { do docente } 1 \text { e mudança de } \\
\text { assunto. }\end{array}$ & $\begin{array}{l}\text { Por conta da } \\
\text { incompreensão do ato } \\
\text { de fala, o pesquisador } \\
\text { termina a conversa } \\
\text { convidando o docente } \\
\text { a continuar explorando } \\
\text { elementos que } \\
\text { necessitam de revisão. } \\
\text { A conversa cobre o } \\
\text { assunto inicial não } \\
\text { continua. }\end{array}$ \\
\hline $\begin{array}{c}\text { Claro, claro... vamos } \\
\text { conversando... Porque eu penso } \\
\text { que quando faz licenciatura, ele } \\
\text { está mais preparado que o outro } \\
\text { pra qualquer função, porque } \\
\text { mesmo que ele faça mestrado, } \\
\text { doutorado, ele vai voltar pra } \\
\text { faculdade... Vai dar aula aqui... } \\
\text { (Docente 1) }\end{array}$ & Pretensão de verdade. & $\begin{array}{c}0 \text { docente } 1 \text { continua } \\
\text { sua fala sobre a } \\
\text { licenciatura, mas } \\
\text { sem possibilidades de } \\
\text { entendimento por falta } \\
\text { de inteligibilidade. }\end{array}$ \\
\hline
\end{tabular}

O que se expressa no quadro 4 diz respeito a um exemplo de análise das manifestações linguísticas - atos de fala - dos participantes sobre um tema em debate, em que se explicita as características comunicativa dessa manifestação. Essa análise, juntamente com a análise proposicional dos atos de fala - construções conjuntas - compõem a caracterização das conclusões sobre o processo instaurado e mantido no GPC.

O que é possível perceber nessa etapa é que a possibilidade de debaterem em um GPC elementos do curso advindos de suas próprias preocupações temáticas faz com que o grupo consiga entender-se sobre os aspectos necessários na promoção de uma formação de professores de Física que não abra mão do envolvimento desses alunos com conceitos físicos e estudos teóricos, mas que também não despreze as necessidades específicas da formação de um professor. Nesse sentido, algumas conquistas desses docentes no plano das concepções sobre a relação do conteúdo específico com a formação de professores de Física são:

\section{- Identificação de possibilidades de mudanças e adaptações em cada disciplina.}

Docente 1: Sim, na semana passada, depois que eu mostrei que a maioria dos relatórios estava muito ruim, eu fui questionando eles sobre as questões dos experimentos pra eles irem explicando, parece que eles comeşaram a ver que precisa explicar com as palavras deles. Pesquisador: Que bom... Então essa proposta que está escrita aí, de promover atividades de discussão e explicação dos relatórios e dos resultados no laboratório é algo ainda passivel de estar em execução. Docente 1: Sim...

- Construção conjunta de entendimentos sobre o papel da disciplina especifica na formacão dos professores.

Pesquisador: E também me interessa a relação dessas disciplinas com as disciplinas de ensino, por exemplo, saber se os alunos estão tendo a oportunidade de trabalbar com o ensino de Física moderna. 
Docente 4: E deveriam, né? Porque tem na escola. Pesquisador: Então, a partir dessas conversas com vocês en vou tentar traçar as relações possíveis entre o laboratório de estrutura da matéria, a estrutura da matéria e a instrumentação para o ensino de Física. Docente 4: "Mas não pode forçar (rindo). Pesquisador: Pensar quais são as possibilidades pode haver de relação, o respaldo que a estrutura pode dar ao laboratório, que o laboratório pode dar para a instrumentação para o ensino, pra que o professor de instrumentação possa se usar do laboratório como instrumento de ensino também.

- Reflexão sobre a própria prática como docentes de cada disciplina na licenciatura em Fisica.

Docente 1: Então, desse jeito que eu estou fazendo, que é muito complicado, todo mundo faæ: Sozinho, mas dai tem um prejuį̃o, e dai eu concordo com você. Mas não tem como aliviar esse prejuizo, porque o grau de comunicação fica muito baixo. O que falta, talvez, e isso que você falou me fez,pensar, é que falte talvez algumas aulas em grupo, algumas aulas antes da prova, por exemplo, algo assim.

- Construção conjunta de entendimentos sobre a importância do planejamento conjunto para a relação entre as disciplinas na licenciatura.

Docente 1: Na minha cabeça, quando a gente planejou o curso, foi assim... Tem Física 2 e logo em seguida, quando acabou o semestre, já ter instrumentação para o ensino de Física 1 e 2... Porque não adianta o cara saber a teoria se não sabe como trabalhar ela... O que nós temos que fazer é juntar as pessoas de laboratório e teóricas e instrumentação está aqui. Isso é lógico, se dá certo, vou tentar fazer aqui com as outras disciplinas... A principio com Física I, depois com os outros professores...

- Debate das discordâncias sobre os aspectos do curso.

Docente 4: Mas, como estamos dizendo, eu acho que essa transposição, esse conceito que eu aprendi com vocês. Mas quem vai ensinar essa transposição? Por exemplo, eu preciso ensinar essa transposição, como vai ser abordado esse conceito de FM no Ensino Médio... tudo bem, esse seria um desafio a ser feito, né? Agora... Estou eu chamado a fazer isso? Ou é que o curso teria que implementar uma disciplina pra isso...

Docente 5: Eu entendo que sim. Pesquisador: Eu acho que todos os professores da licenciatura podem estar convidados a fažer isso, ao menos a pensar nisso, pensar em atividades, situações em que o aluno possa se explicar em Física Moderna, lecionar conceitos, essas coisas que não diminuem a Física, mas também se mostram na outra parte... Docente 4: Mas também entendo que, devido ao tanto de atividades que têm os professores, cada um faça individualmente e por alto... Por exemplo... Aí é mais complicado, né?... porque é muita coisa.

Do ponto de vista comunicativo, resultante da análise da força ilocucionária dos discursos - exemplificada no quadro 4 - , apresentam-se os três principais elementos sintetizadores dentre as diversas sínteses das características comunicativas selecionadas para o tema, ou seja, sobre a influência da participação no GPC nas características das argumentações utilizadas pelos professores:

- Transição do discurso pautado somente nos mundos objetivo e subjetivo para o mundo social também.

- Construção de "entendimentos" sobre aspectos relativos à diferença entre as áreas e os princípios importantes na formação do professor de Física.

- Coordenações de ações individuais voltadas à concretização do todo.

Ou seja, no que se refere ao benefício de uma condução do trabalho do GPC pautado nos princípios da TAC, pode-se inferir que os professores, juntamente com o pesquisador, por desenvolverem uma argumentação de modo a buscar o entendimento, acabam constituindo concepções conjuntas acerca das 
necessidades próprias da licenciatura e sobre o papel das disciplinas específicas na formação do futuro professor, tais como:

Quadro 5: Exemplos de conclusões conjuntas do grupo sobre a licenciatura e o curso.

\begin{tabular}{|c|c|}
\hline Síntese dos atos de fala & Construção do pesquisador \\
\hline $\begin{array}{l}\text { Proposta de inclusão das construções } \\
\text { conjuntas do grupo nos documentos do curso. }\end{array}$ & $\begin{array}{c}\text { A necessidade apontada pelo grupo de incluir } \\
\text { as conclusões sobre as necessidades da } \\
\text { licenciatura nos documentos do curso mostra, } \\
\text { além de um entendimento conjunto sobre } \\
\text { as propostas, também a consciência de sua } \\
\text { importância. }\end{array}$ \\
\hline $\begin{array}{l}\text { Conclusão conjunta de que há uma } \\
\text { necessidade de espaços onde essa } \\
\text { conversa seja possível entre os docentes no } \\
\text { departamento. }\end{array}$ & \multirow{2}{*}{$\begin{array}{l}\text { Com uma preocupação comum, os docentes } \\
\text { encontram vários pontos carentes de reflexão } \\
\text { e mudança dentro das estruturas e formas } \\
\text { de trabalhos nas suas disciplinas e também } \\
\text { no que se refere ao papel dos alunos nesse } \\
\text { cenário, concluindo, no que chamaremos de } \\
\text { "elucidações conjuntas", as deficiências que } \\
\text { podem ser atacadas pelo grupo ao longo das } \\
\text { outras reuniões. }\end{array}$} \\
\hline $\begin{array}{c}\text { Não deve haver diferenciação de conteúdo } \\
\text { nem de formas de avaliação entre o } \\
\text { bacharelado e a licenciatura. }\end{array}$ & \\
\hline $\begin{array}{l}\text { Constatação de que há a necessidade de } \\
\text { promover uma revisão nas ementas das } \\
\text { disciplinas de Instrumentação para o Ensino } \\
\text { de Física em busca de suas especificidades. }\end{array}$ & \multirow{2}{*}{$\begin{array}{c}\text { A partir das elucidações conjuntas surgem } \\
\text { dos docentes várias propostas de melhora } \\
\text { ou mudança que são discutidas e apontadas } \\
\text { como caminho para se aproximar as } \\
\text { disciplinas - ou melhorá-las. }\end{array}$} \\
\hline $\begin{array}{l}\text { Proposta de leitura do PPP do curso e de } \\
\text { continuidade da conversa. }\end{array}$ & \\
\hline
\end{tabular}

Uma sistematização das construções conjuntas realizadas pelos docentes, no que se refere às necessidades do curso e de suas disciplinas e aos planejamentos de ações efetivas de mudança, é mostrada na figura 2:

Figura 2: Sistematização das conclusões gerais alcançadas pelo GPC e das propostas de mudança.

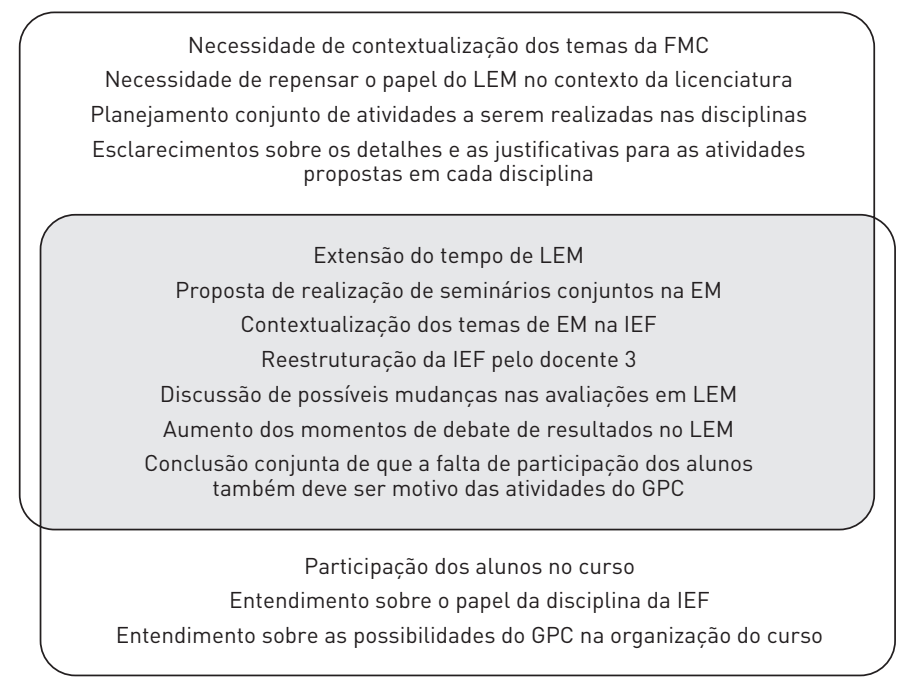

Revista Ensaio | Belo Horizonte | v.16 | n. 02 | p. 85-106 | maio-ago | 2014 


\section{CONSIDERACְ̃̃ES FINAIS}

As análises de todas as reuniões realizadas no período de um ano pelo GPC permitem construir uma avaliação sobre o processo planejado e instaurado ao longo de seu desenvolvimento no que diz respeito ao potencial desse tipo de ação com os docentes da licenciatura em Física.

As sínteses dos elementos do processo mostram um avanço no campo das ações e no campo das concepções. No campo das concepções, os docentes que iniciavam o trabalho fundamentados pela racionalidade técnica já descrita, ao longo do processo, passam a reconhecer as validades específicas da licenciatura, as importâncias referentes à contextualização dos conteúdos, a relação entre conteúdos e práticas, a importância da prática pedagógica nas disciplinas específicas e, principalmente, os docentes começam a se entender sobre a necessidade da manutenção de um planejamento conjunto das disciplinas para garantir que elas sejam ministradas com qualidade.

Das características específicas do processo de instauração de um ambiente possibilitador do agir comunicativo, é possível observar muitas coordenações de ação individuais com vistas ao desenvolvimento do todo proposto pelo grupo, muitas argumentações sobre elementos técnicos da elaboração das disciplinas e, principalmente, podemos observar um movimento dos participantes para o mundo social, se desprendendo somente dos mundos objetivo e subjetivo.

Como foi verificado nos quadros de análise e nas sintetizações dos elementos do processo, é imprescindível olhar para o conjunto de construções e propostas realizadas pelos participantes do grupo ao longo das reuniões e como alguns aspectos tidos como importantes pelos referenciais começam a ser contemplados quando as discussões se desenvolvem.

$\mathrm{Na}$ premissa de desenvolvimento de um ambiente onde há uma equidade de oportunidades, o respeito à opinião dos outros participantes e o debate aberto e democrático, observamos os docentes e o pesquisador começarem a se posicionar como um grupo único, sem as diferenças hierárquicas e, aos poucos, exporem abertamente suas concepções e suas práticas em sala de aula, colocarem em dúvidas seus próprios métodos e se questionarem sobre a validade da forma como conduzem suas disciplinas em comparação com um projeto que deve se pretender de formação de professores de Física.

Enfim, a constituição de um GPC com os docentes das disciplinas que envolvem os conteúdos de FMC se constituiu como uma tentativa de estabelecer uma relação intersubjetiva entre os docentes. As preocupações temáticas eram próximas e foram tematizadas no início, possibilitando muitos momentos de entendimento sobre aspectos antes divergentes.

Ao tomar a interação comunicativa como princípio para a constituição de um processo formativo dos professores que lecionam na licenciatura, pode-se entender que as construções conjuntas empreendidas pelos docentes e os momentos de tematização da prática, assim como as ações efetivadas, mostram possibilidades 
reais de continuação deste GPC e, principalmente, mostram as mudanças nas concepções dos participantes sobre o papel das disciplinas específicas na licenciatura em Física.

Pelas razões descritas, defende-se a ideia de formação de grupos de estudo e planejamento conjunto entre docentes da licenciatura como uma forma de superar a racionalidade técnica instituída na universidade e proporcionar aos docentes que, em grupo, reflitam, planejem suas disciplinas e instituam as mudanças cabíveis e necessárias no contexto de cada curso de licenciatura em Física.

\section{REFERÊNCIAS}

BARDIN, L. Análise de Conteúdo. Lisboa: Edições 70, 2007.

CARR, W.; KEMMIS, S. Teoría crítica de la enseñanza: la investigación-acción en la formación del professorado. Barcelona: Martínez Roca, 1988.

CHAPANI, D. T. Políticas públicas e formação de professores de ciências: uma análise a partir da teoria social de Habermas. Orientadora: Lizete Maria Orquiza de Carvalho. 2010. 421 f. Tese (Doutorado em Educação para a Ciência). Faculdade de Ciências da Uinversidade Estadual de São Paulo - Campus de Bauru, Bauru, 2010.

CHAUÍ, M. Escritos sobre a universidade. São Paulo: Editora UNESP, 2001.

COUTINHO, C. P. Investigação-ação: metodologia preferencial nas práticas educativas. Psicologia, Educaşão e Cultura, Braga, v. 13, n. 2, p. 455-479, 2009.

CUNHA, M. I. Diferentes olhares sobre a prática pedagógica no ensino superior: a docência e sua formação. Revista Educação, Porto Alegre, v. 3, n. 54, p. 525-536, Set./Dez. 2004.

FREITAS, Z. L. Um projeto de interação universidade-escola como espaço formativo para a docência do professor universitário. Orientadora: Lizete Maria Orquiza de Carvalho. 2008. 147 f. Tese (Doutorado em Educação para a Ciência) - Faculdade de Ciência, Universidade Estadual Paulista "Júlio de Mesquisa Filho". Bauru, 2008.

GOERGEN, P. L. Ciência, Sociedade e Universidade. Educação e Sociedade, Campinas, v. 19, n. 63, p. $53-79,1998$.

GOMES, L. R. O consenso na teoria do agir comunicativo de Habermas e suas. Universidade Estadual de Campinas. Campinas, p. 159. 2005.

HABERMAS, J. Teoria do agir comunicativo 1: Racionalidade da ação e racionalização social. Tradução de Paulo Astor Soethe. 1. ed. São Paulo: Martins Fontes, 2012. 704 p.

KEMMIS, K.; MCTAGGARD, R. Cómo planificar la investigaciín-acción. Barcelona: Laertes, 1988.

LONGHI, A. J. A ação educativa na perspectiva da teoria do agir comunicativo de Jurgen. Campinas: Universidade Estadual de Campinas, 2005. 173 p.

MUHL, E. H. Racionalidade comunicativa e educação emancipadora. Orientador: Pedro Laudinor Goergen. 1999. 287 f. Tese (Doutorado em Educação). Faculdade de Educação, Universidade Estadual de Campinas, Campinas, 1999.

MUHL, E. H. Habermas e a educação: ação pedagógica como agir comunicativo. Passo Fundo: UPF Editora, 2013.

OSTERMANN, F. O debate sobre as Licenciaturas em Física no Brasil. Conferência da Sociedade Brasileira de Física. [S.l.]: [s.n.]. 2001.

ROSA, M. I. F. P. S.; SCHNETZLER, R. P. A investigação-ação na formação continuada de professores de ciências. Ciência e Educação, Bauru, v. 9, n. 1, p. 27-39, 2003. 
SUTIL, N. Negociações e formação de professores de física: construções conjuntas e resolução de conflitos em problematização da prática educacional. Orientador: Lizete Maria Orquiza de Carvalho. 2011. 227 f. Tese (Doutorado em Educação para a Ciência). Faculdade de Ciências, Universidade Estadual de São Paulo - Bauru, 2011.

TRIPP, D. Pesquisa ação: uma introdução metodológica. Educação e Pesquisa, São Paulo, v. 31, n. 3, p. 223-466, set./dez. 2005.

Data Recebimento: 14/08/2013

Data Aprovação: 25/03/2014

Data Versão final: 25/03/2014

\section{Contato:}

Universidade Federal de Itajubá

Instituto de Física e Química

Avenida BPS, $n^{\circ} 1303$ - Bairro Pinheirinho - Itajubá, MG - Brasil

CEP: $37500-403$ 